\title{
Female and Male Community-Level Empowerment: Capability Approach-Based Findings for Rural India
}

\author{
Melinda Schmidt ${ }^{1} \cdot$ Harald Strotmann ${ }^{2}\left(\mathbb{C} \cdot\right.$ Jürgen Volkert ${ }^{2}(\mathbb{0}$
}

Accepted: 29 January 2021 / Published online: 22 March 2021

(c) The Author(s) 2021

\begin{abstract}
This paper adds to the empirical research on empowerment drivers by analysing the empowerment of women and men at the community level. Using micro-data from four villages in rural Karnataka/India, our econometric estimations confirm several predictions of Sen's capability approach on potential determinants of empowerment. Education, decent employment, other-regarding agency goals, political networks, trust and fairness coincide with reported impact on community-level change. Gender-specific estimations demonstrate that most empirical drivers of empowerment are quite consistent for men and women in many respects. Some variables, however, notably higher education, correlate with community-level empowerment of men, but not of women, which emphasises different gender roles in rural Karnataka. These findings may help researchers and practitioners to further develop cause-related strategies to overcome major determinants of disempowerment in institutional village decision contexts in general as well as those which are gender-specific.
\end{abstract}

Keywords Community-level empowerment · Capability approach · Gender · Rural India $\cdot$ Human development · Agency

\section{Résumé}

Cet étude contribue aux recherches empiriques sur les facteurs d'autonomisation grâce a l'analyse de l'autonomisation des femmes et des hommes au niveau communautaire. Utilisant des micro données de quatre villages rurales au Karnataka, en Inde, nos estimations économétriques confirment plusieurs des prédictions concernant

Harald Strotmann

harald.strotmann@hs-pforzheim.de

Melinda Schmidt

melindaschmidt@web.de

Jürgen Volkert

juergen.volkert@hs-pforzheim.de

1 Barcelona, Spain

2 Pforzheim University, Tiefenbronner Str. 65, 75175 Pforzheim, Germany 
l'approche des capacités de Sen sur les déterminants potentiels de l'autonomisation. L'incidence signalé sur les changements au niveau de la communauté coïncide avec l'éducation, des emplois décents, les objectifs des agents visant les autres, les réseaux politiques, la confiance et l'équité. Les estimations spécifiques à chaque genre montrent que la plupart des facteurs d'autonomisation empiriques sont consistent pour les hommes et les femmes dans plusieurs respects. Toutefois, certaines variables, notamment une éducation plus élevée, sont corrélés avec une autonomisation au niveau communautaire des hommes, mais pas des femmes, ce qui souligne les différents rôles des genres au Karnataka.

\section{Introduction}

"Development is fundamentally an empowering process" (Sen 2009, p. 249). As such, the concept of empowerment has increasingly attracted the attention of scholars and policy makers interested in human development research or policies (Mitlin 2013, p. 54).

Given the importance of empowerment analyses for human development and related policies, numerous studies have analysed and discussed determinants and strategies of women's empowerment (e.g. Alkire et al. 2013; Anand et al. 2020; Datta 2015; Narayan 2005; Swain and Wallentin 2009). However, most of these empirical studies have exclusively focused on female empowerment. Many fewer contributions are related to the determinants of women's and men's empowerment. Moreover, the empowerment to bring about change in one's community has often been neglected, while focusing on women's empowerment in household decision-making (Trommlerova et al. 2015, p. 1).

Considering these research gaps, the goals of this paper are to empirically analyse potential determinants of empowerment at community level in general, to specify gender-specific drivers of empowerment for men and women and to identify common determinants. In Sect. 2, we reconsider theoretical foundations of the underlying capability approach (CA), of power analysis and of empowerment. Building on this, we explain our empirical methodology as well as the data in Sect. 3. Related to Sen's (1999, pp. 18-19) notion of a human being as an agent "who acts and brings about change" we will analyse the self-reported capability of villagers that "people like themselves" can bring about change in the community, which captures important aspects of "power with" other community members (Ibrahim and Alkire 2007, p. 395).

The empirical analyses in Sect. 4 apply ordered probit and generalised probit models, to examine the possible role of CA-related determinants of community-level empowerment while controlling for major socio-demographics. We finally discuss our empirical findings and conclude with perspectives and the relevance of our findings for practitioners and researchers in Sect. 5. 


\section{Foundations}

\section{Theoretical Concepts: Capabilities, Agency, Power and Empowerment}

The CA aims to enhance the "real freedoms" (Robeyns 2017, p. 39) of human beings (Sen 2017, p. 34). Capabilities are freedoms of persons "to lead the kind of life they value and have reason to value" (Sen 1999, p. 18). They comprise what a person is able to do and be.

Whether people can achieve a life that they value, and have reason to value, depends on the restrictions they face in the dimensions of well-being they personally value.

For our analysis, we apply Sen's concept of an agent as "someone who acts and brings about change" (Sen 1999, p. 19). Hence, people are supposed to act and realise changes in their life to overcome their restrictions. Agency goals are not limited to enhancing the own individual well-being but can also include other-regarding goals and commitments on behalf of one's society (Ibrahim 2014, p. 54). Empowerment is conceptualised as the expansion of the constructive agency of people who foster development based on an enhancement of their effective freedom (Sen 2009, p. 249; Ibrahim and Alkire 2007, p. 384). This concept of empowerment resonates the perception of power in the sense of "power to".

"Power to" is essential to shape one's own life and to the capacity to act, for the exercise of agency, and the realisation of rights, citizenship or voice (Gaventa 2006, p. 24; Frediani et al. 2019, p. 105). A precondition is the autonomy of a person to make decisions within certain fields. Autonomous decisions are decisions which a person makes based on own values and life goals, rather than just responding in compliance with other people's goals, claims or expectations (Ibrahim and Alkire 2007, pp. 391-394).

However, other forms of power and powerlessness can challenge this power to act:

Generally, "power over" challenges "power to" when some actors can or do affect the actions or thoughts of the powerless. "Power over" is exercised through visible, hidden and invisible power.

- "Visible power" affects the actions and thoughts of the powerless through dominant groups which prevail in visible conflicts based on political bargaining and decision-making (Gaventa 2006, p. 25).

- "Hidden power" is based on shaping and setting the political agenda and controlling who will effectively participate and contribute to the political agenda. It results in a "mobilisation of bias", i.e. in "predominant values, beliefs, and institutional procedures ('rules of the game') of the powerful" (Lukes 2005, pp. 20-21). The powerless who continuously lose in political arenas of a community may develop an unconscious pattern of withdrawal (Lukes 2005; Gaventa 2006, 1980).

- "Invisible power" (Gaventa 2006, p. 29) emerges when powerful actors succeed in shaping the perceptions of the powerless, their beliefs, desires and acceptance 
of the status quo (Lukes 2005, p. 9; Gaventa 1980). The powerful define what is normal and safe so that the powerless accept own exclusion through internalisation of powerlessness within a "culture of silence".

Overcoming the interrelated and accumulated effects of visible, hidden and invisible power (Gaventa 1980, p. 23) requires strengthening the "power within" and "power with" of the powerless.

"Power within" is based on the sense of self-identity, confidence, awareness and power within an individual. It is a precondition for action which requires a person's sense of self-worth and self-respect. (Frediani et al. 2019, p. 105; Gaventa 2006, p. 24).

Power and powerlessness in a community are the products of social, economic and political structures. In the light of these power structures, individuals in a subordinated position may have problems to bring about change at the community level (Ibrahim 2014). Therefore, they have to gain sufficient acceptance, respect or support by others to have enough power with others to achieve their own agency goals in the community (Eyben et al. 2006). This reflects Sen's (2009) ideal of an individual who is supposed to be able to achieve own agency goals in a democracy in the sense of "government by discussion" through broad, intensive participation and public reasoning.

"Power with" therefore encompasses being able to find common interests and to build collective strength through synergies derived from partnerships, collective action and alliances (Gaventa 2006, p. 24; Frediani et al. 2019, p. 105). It captures the power, which is available for someone with other community members to overcome social restrictions and change aspects at a community level (Ibrahim and Alkire 2007, pp. 394-395). Sufficient trust as a precondition of any cooperation (Ostrom 2000) is a precondition of the "power with".

Individual agency and empowerment alone may not suffice to develop a countervailing power against dominant elite coalitions (Gaventa 1980, p. 25; Ibrahim 2014). To achieve this, the joint effort of groups with common goals and interests together with social capital and resources can facilitate the convergence of individual agency into collective agency and community empowerment (Tiwari 2014, p. 43). Thus, "power with" is determined by individuals and groups releasing their power through self-interrogation or consciousness raising (Eyben et al. 2006, p. 8). Therefore, "power with" encompasses both individual and collective agency. Nevertheless, based on collective agency and empowerment, group members can generate capabilities, which a single member would be unable to have or achieve (Ibrahim 2014, p. 69). Hence, while an individual may be unable to achieve change at the community level, collectively he or she can do so as part of the community, thereby creating community empowerment.

As collective agency and empowerment converge out of individual agency (Tiwari 2014, p. 43), these two kinds of agency are distinct but interdependent. Interdependencies explain why several aspects potentially affect different kinds of power and empowerment. For instance, fairness is a prerequisite of cooperation and of the resulting "power with", but it can also impact the "power within", notably for individuals' sense of self-worth and self-respect.

The empirical analyses in this paper will focus on potential determinants of community-level empowerment as one important aspect of this "power with". 


\section{Theoretical Capability Approach Relations to Potential Drivers of Community-Level Empowerment and Existing Empirical Research}

Existing empirical evidence for India on drivers of empowerment so far mainly refers to studies on women empowerment, often with respect to their role in household decision contexts (see, e.g. Anand et al. 2020; Chakrabarti and Biswas 2012; Datta 2015; Garikipati 2008; Leach and Sitaram 2002). Corresponding micro-data studies for India for men and quantitative studies focusing on aspects of "power with" at the community level (Ibrahim and Alkire 2007) are missing to the best of our knowledge and are also rare in the literature for other countries. Exceptions are the studies of Trommlerova et al. (2015) for The Gambia and Lokshin and Ravallion (2005) for Russia. The following empirical analyses contribute to filling this gap and assess potential determinants of the self-reported capability of people to bring about change at the community level. Therefore, in this section, hypotheses about possible drivers of community-level empowerment are derived based on the CA. They are supplemented, where meaningful, with existing empirical research on empowerment in general.

In the CA, education (e. g. overcoming illiteracy) is indispensable as a precondition of autonomy for making informed, rational choices and of empowerment in general (Burchi et al. 2015, p. 26). A variety of existing studies confirm the impact of education on female empowerment (see, e.g. Kishor and Gupta 2004 for India or Jejeebhoy and Sathar 2001 for India and Pakistan).

Decent employment can be interpreted in the sense of having good and suffcient employment (Sen 1997). Lack of good employment (e.g. bad types of work and labour conditions) often violates a person's "power within". This may impair personal self-worth and self-respect, as major determinants of empowerment at the community level. Allendorf (2012) shows a significantly positive impact on agency for women working outside their homes in India.

The fact that people search for more work can be assumed to indicate perceived individual agency freedom, which may strengthen their sense of self-worth, status, self-confidence and their social bases of self-respect (Sehnbruch et al. 2020, p. 6) and thus imply more impact at the community level.

Health can be an important determinant of the ability to impact change. Trommlerova et al. (2015) find that individuals in good health report higher levels of empowerment at both individual and community levels.

Financial autonomy, notably being able to expend one's income or wealth, and access to financial services provides empowerment opportunities (Arora 2014, p. 799) so that one will not have to give up own personal life goals due to economic dependency on others. Chakrabarti and Biswas (2012, p. 175) find for India that greater financial independence as measured by women's occupational status may increase their level of empowerment. 
Sen (2009, pp. 259 and 271) emphasises that agency goals may comprise of goals related to one's self-interest but also of other-regarding agency goals beyond the own well-being. For instance, Sen $(2017$, p. 30) criticised that the responsibility to care for infants and the elderly is often-unfairly-imposed on women. Generally, a person may accept a decline in her or his well-being in order to care for personal commitments related to other human beings or the whole community. Hence, a reduction of a person's well-being does not necessarily indicate a failure to pursue one's goals; rather, based on the individual's other-regarding agency goals, one may deliberately forego one's own well-being in order to improve the well-being of other people or the community. With this, she or he is thereby actively pursuing her or his own other-regarding agency goals.

Political freedoms, notably political participation, are important to achieve one's life goals (Sen 1999, p. 54). They enhance people's capabilities by providing a voice in the political process. Missing political participation may result in a political neglect of certain groups and their life goals (Volkert 2006, pp. 375-376). Political participation and networks can thus be possible drivers for the ability to generate changes at community level. For women in India e.g. Deininger et al. (2012) find that political reservations and thus improved political participation can help to empower women.

For people devoting their agency to a cooperation with other community members, also trust is a critical precondition for their empowerment (Ostrom 2000, p. 153).

The fairness of a cooperation is imperative for a cooperation to persist. Fairness also encompasses primary goods, notably the social bases of self-respect as a precondition of empowerment. Self-respect depends on the respectful treatment by others. Without self-respect, pursuing one's life goals may not seem worthwhile, as the will to achieve them may decline (Rawls 1996, pp. 308-309 and 318-319) because of a lack of "power within". Being respected and the resulting social bases of self-respect are part of Nussbaum's (2011, pp. 33-34) core capabilities. Further, lack of fairness and self-respect negatively affect the capability to appear in public without shame (Sen 2009, p. 256). Trommlerova et al. $(2015$, p. 8) find that being treated in a fair and respectful way may reduce the need for change, but the perceived community-level empowerment can increase as respect and fairness are enablers of social cooperation.

Also, socio-demographic characteristics play a role. Notably gender is an important determinant of empowerment. The National Family Health survey shows that the majority of women in Karnataka, e.g. need the permission to participate in public life and go out by themselves (IIPS and ICF 2017, p. 27). Moreover, it finds an increase of women's empowerment with age, measured by the level of participation in household decision-making (IIPS and ICF 2017, p. 26).

Caste as a structural constraint may play an important role in a person's capability set (Robeyns 2017, p. 65). Mosse (2018) demonstrates how castes are still an important contributor to persisting socio-economic disparities in India.

Household heads can have a higher level of self-reported community-level empowerment than other family members as they might be more respected at community levels than other villagers. Trommlerova et al. (2015), however, observe a negative correlation for The Gambia. This might be explained by the burden of high responsibilities of a household head or by more awareness of potential restrictions. Being married may also lead to more respect and higher self-rated empowerment. 
Table 1 Potential sociodemographic and CA-based drivers of empowerment and their expected impact on community-level empowerment

\begin{tabular}{ll}
\hline $\begin{array}{l}\text { Potential drivers of community-level } \\
\text { empowerment }\end{array}$ & Expected impact \\
\hline $\begin{array}{l}\text { Socio-demographic characteristics } \\
\text { Gender }\end{array}$ & Larger for men \\
Age & Increases with age \\
Caste & Smaller for lowest castes \\
Marital status & Larger for married people \\
Head of household & Unclear \\
CA-based drivers & \\
Education & + \\
Decent employment & + \\
Search for more work & Unclear \\
Self-reported health & + \\
Financial autonomy & + \\
Other-regarding agency goals & + \\
Political networks and participation & + \\
Trust & + \\
Fairness & + \\
\hline
\end{tabular}

Source Own illustration

Table 1 summarises our main hypotheses on potential determinants of empowerment at community level derived from the CA that will be empirically assessed in the following.

\section{Data and Empirical Operationalisation of Drivers of Community-Level Empowerment}

\section{Dataset}

Our dataset stems from a household-level survey conducted in 2017 in four villages in rural Karnataka in India. The survey is part of the independent scientific evaluation of the "Model Village Project" of the Bayer Crop Science AG. It contains information on both households and individuals. The survey questions are based on the theoretical framework of Sen's $(1983,1999)$ CA and collect information on core socio-demographic characteristics, but also on different dimensions of well-being, including economic means, consumption, health issues, education, subjective and reported well-being, social relations, trust, fairness and agency. The questionnaire was translated into the local language, Kannada, for face-to-face interviews. The survey is representative for the four villages. It includes all social strata and castes and covers around $75 \%$ of all households in the villages. Thereby, the head of each household and additional adult household members have been interviewed. In total, the sample consists of more than 1000 
households and 2400 individuals. For our analyses, we can use 1925 observations on individuals with valid responses for all included variables.

\section{Operationalisation of Empowerment at the Community Level and Its Potential Drivers}

The dependent empowerment variable used focuses on the perceived ability of people to collectively change things, if they want, in their community (Ibrahim and Alkire 2007, p. 395). The question used to capture the community dimension was proposed by Ibrahim and Alkire (2007, p. 395) and asks the following:

If you have any problem in your village/community and you want to change it, do you feel that people like you can generally make such changes?

Even though the dependent variable is measured at an individual level, it does not only refer to the villagers' individual agency, but also to the collective empowerment of "people like you" at the community level and thus measures important aspects of "power with".

Responses on a 5-digit Likert-scale range from "Yes, very easily", "Yes, fairly easily", "Yes, but with some difficulties", "Yes, but with great difficulties", to "No, not at all". For our analyses, we aggregate them to the three categories "Yes, easily", "Yes, but with difficulties", and to "No, not at all".

For the 1925 villagers included into our multivariate analyses, about 16\% answered that they can "not at all" make those changes, $43 \%$ responded that they can make changes, but "only with difficulties" (7\% with great and $36 \%$ with some difficulties), and $41 \%$ indicated that they can achieve change "easily" (39\% fairly easy and $2 \%$ very easy).

Table 2 presents our operationalisation of the potential CA-based drivers derived in Sect. Foundations and the set of standard variables that control for possible impacts of differences in socio-demographic characteristics. Dummy variables for the four villages take account for potential differences between the villages. Descriptive statistics are given for the 1925 observations used in our estimations.

\section{Econometric Methods and Results of Empirical Analyses}

\section{Estimation Methods}

To empirically examine the impact of these potential drivers of empowerment on self-reported influence on the community level, we estimate multivariate discrete choice models that consider that the dependent variable is categorical (see, e.g. Greene 2018). To analyse whether our empirical findings are robust to the method used, we apply (1) ordered probit models and (2) generalised ordered probit models which relax the proportional odds assumption of the ordered probit models for those variables for which this assumption does not hold (see Williams 2016). The generalised ordered probit model thus estimates one coefficient for each variable under the 


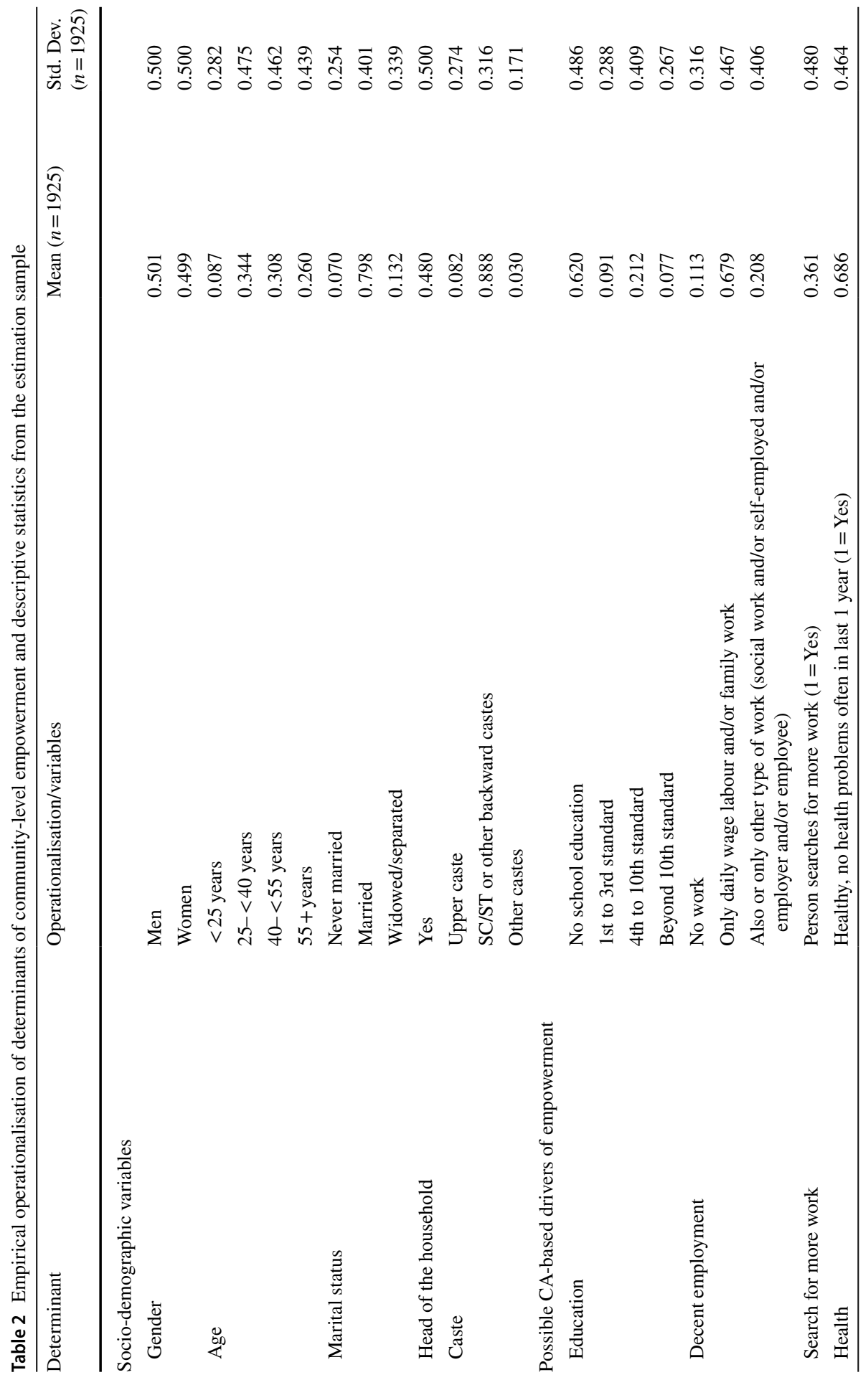

站。 


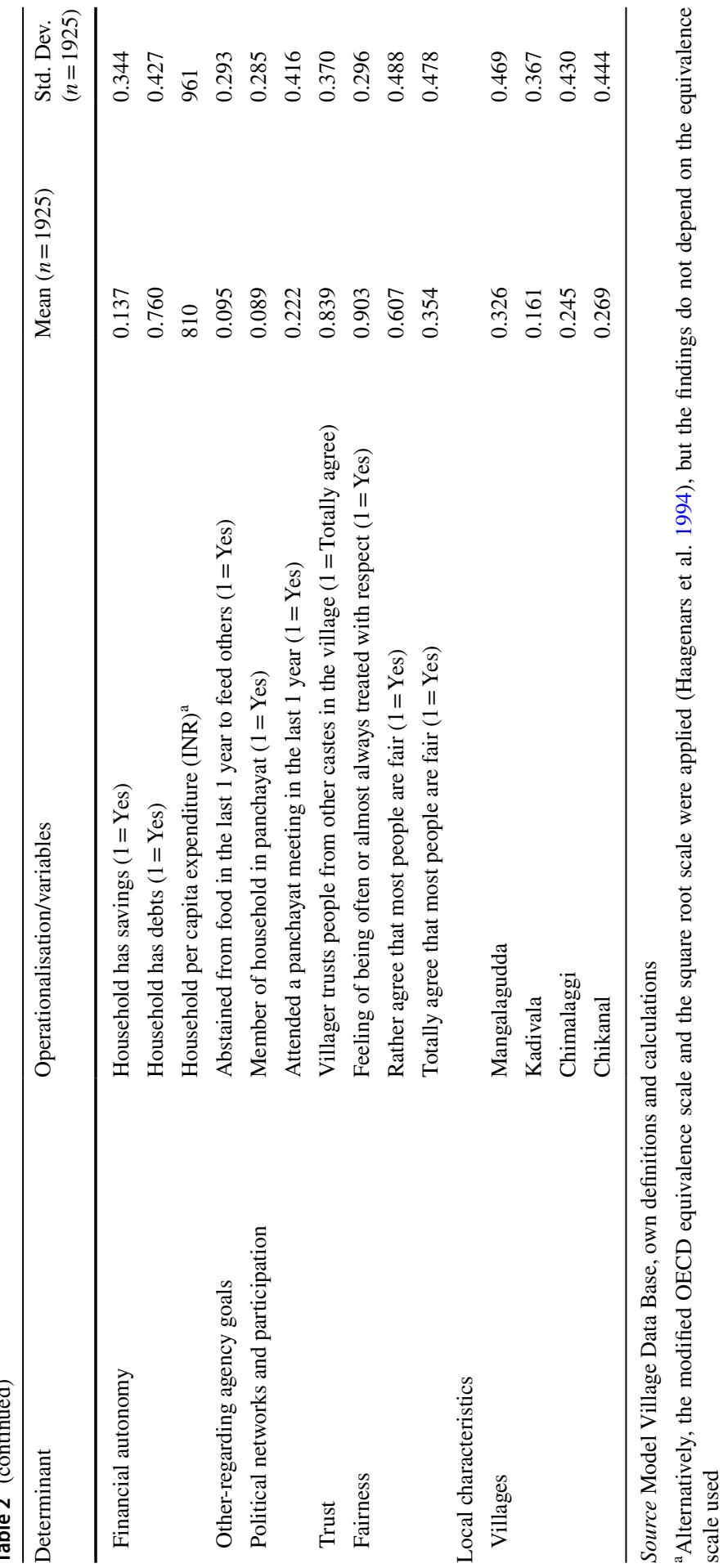


parallel odds assumption. For variables for which this assumption is violated, two coefficients are estimated. For the test of the parallel lines assumption, we apply a $5 \%$-level of significance. An advantage of generalised ordered probit models is that they are more parsimonious and interpretable than those estimated by, e.g. multinomial logistic regressions.

As already mentioned in Sect. Operationalisation of Empowerment at the Community Level and Its Potential Drivers, the dependent variable is an ordered categorical variable with three categories of being able to make changes (0) "Not at all" or (1) "Only with difficulties" or (2) "Easily". Positive coefficients of the independent variables thus imply a positive impact of the variable considered on the reported ability that "people like you" can make changes at the community level. Observations are not independent for people from the same household. Therefore, our estimation of robust standard errors accounts for possible intra-household correlation of standard errors for all regression methods.

\section{Empirical Results for Models Estimated for All Villagers}

As some of the socio-demographic variables, like gender, age or caste, might correlate with some of the other explaining variables, like education or type of work, Table 3 first shows the results of the estimation of a baseline model with only sociodemographic variables. Column (1) presents the results of the ordered probit estimation and columns (2) and (3) of the generalised ordered probit estimation. Thereby, column (2) reports estimates for the comparison between "change is not at all possible" and the other categories, while column (3) compares "not at all" or "yes, with difficulties" with "change is easily possible".

In general, our empirical estimation results confirm the expected correlations with empowerment at the community level. In the villages considered, the selfreported feeling to be able to bring about change in the community is...

- ...significantly lower for women than for men at a 5\%-level of significance ( $P$-values 0.018 and 0.026$)$. The marginal effect for the probability, to be able to bring about change easily, is according to the ordered probit model about 5.4 percentage points lower for women than for men.

- ...significantly higher for villagers aged 40 to 55 years compared to villagers younger than 25 years at a $10 \%$-level of significance.

- ...significantly lower for villagers from the lowest castes (scheduled tribes, scheduled castes, other backwards castes) compared to upper caste villagers ( $P$-value 0.062$)$.

- ...significantly lower for the head of the household than for other respondents at a $1 \%$-level of significance. The generalised ordered probit model demonstrates that this difference stems from a significantly lower probability of heads saying that change is easily possible. 


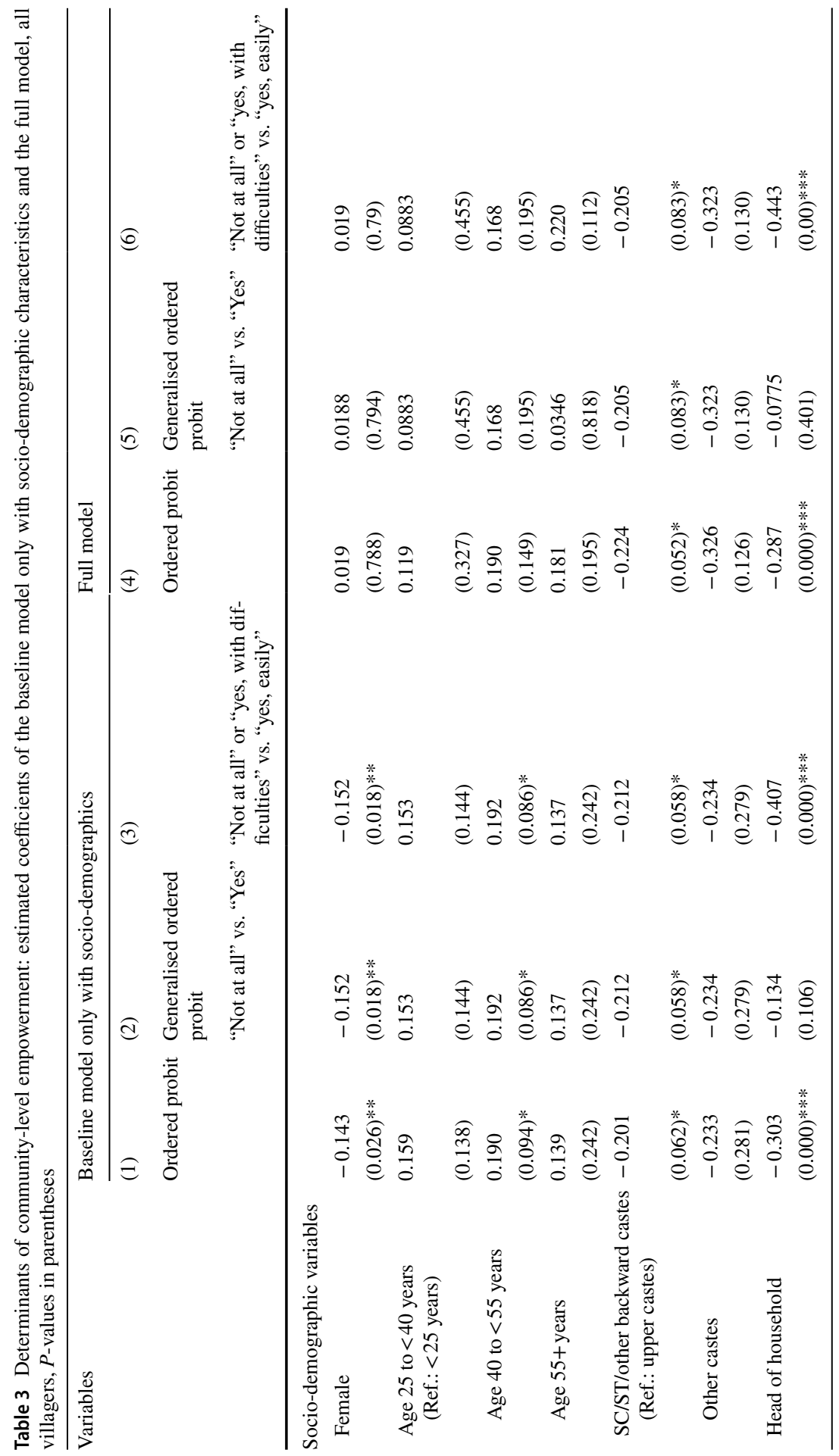




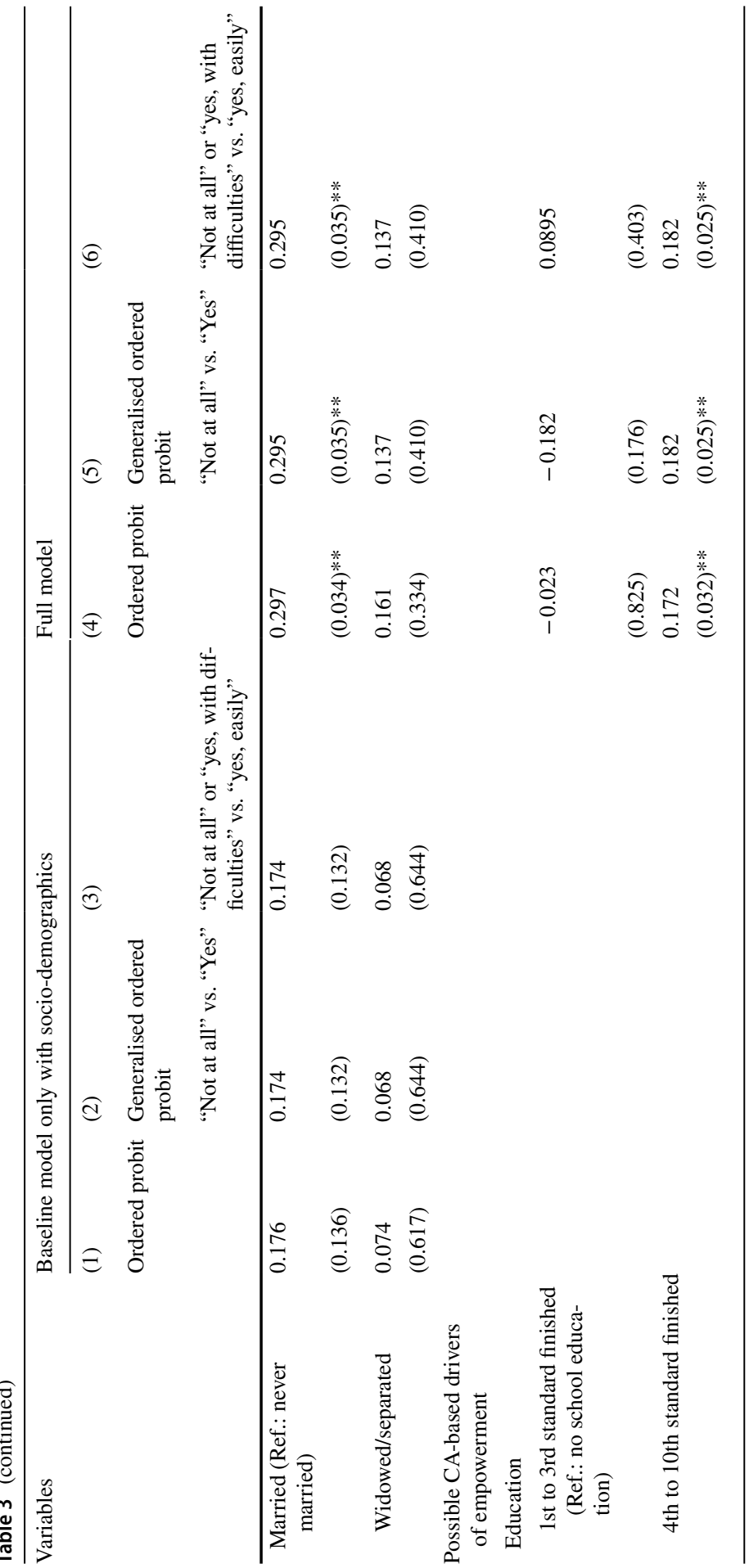

站。 


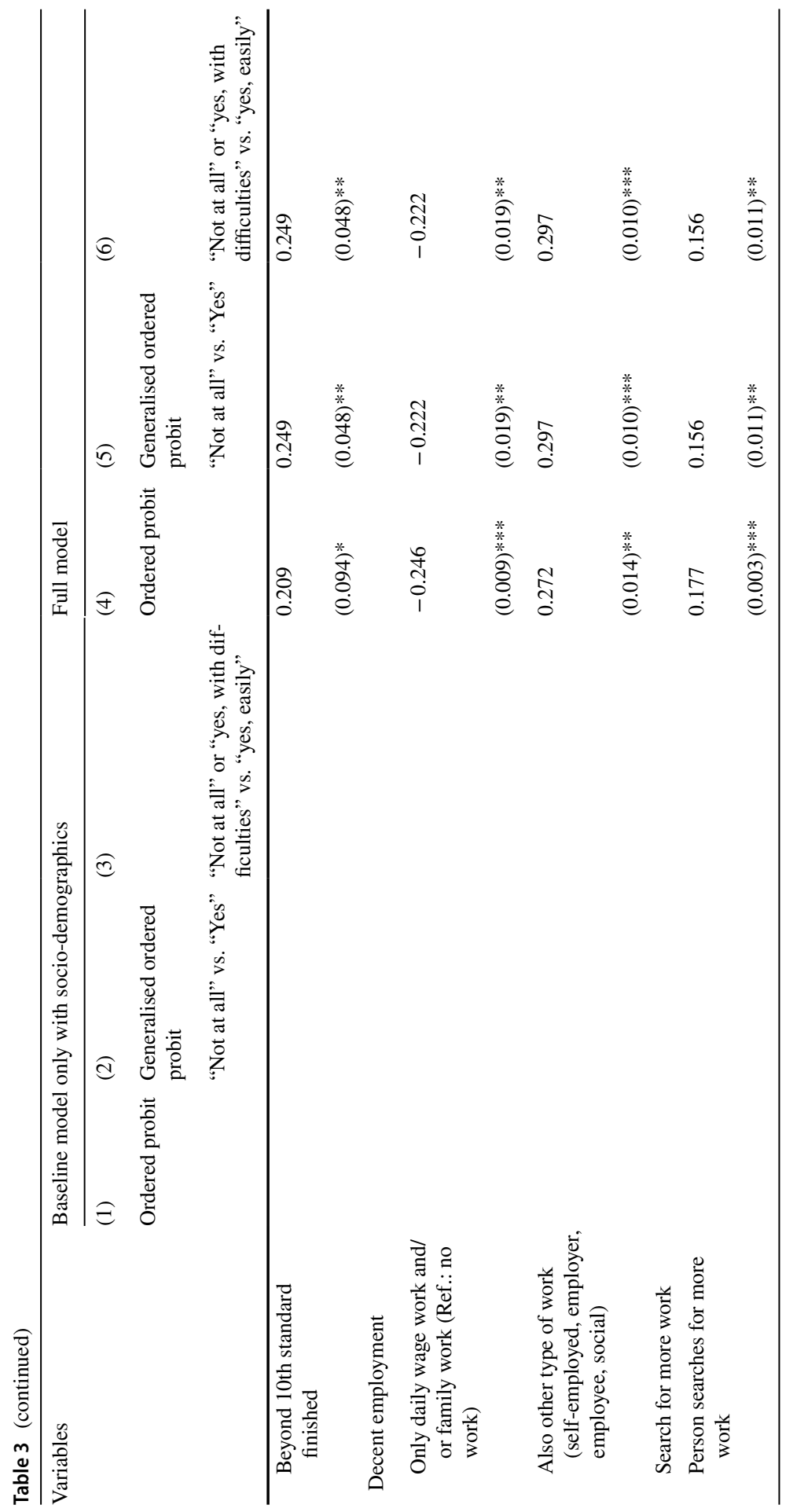




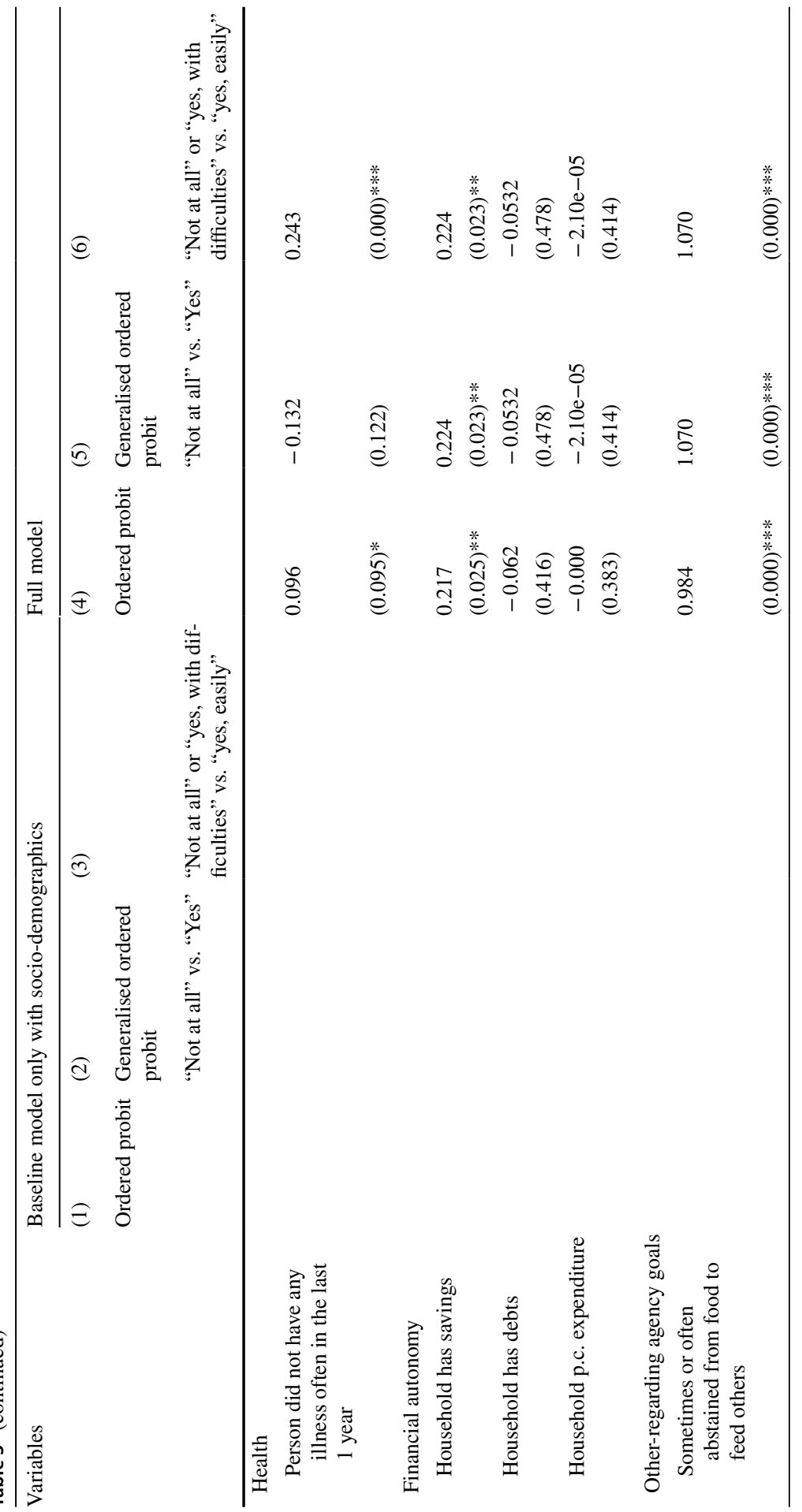

站。 


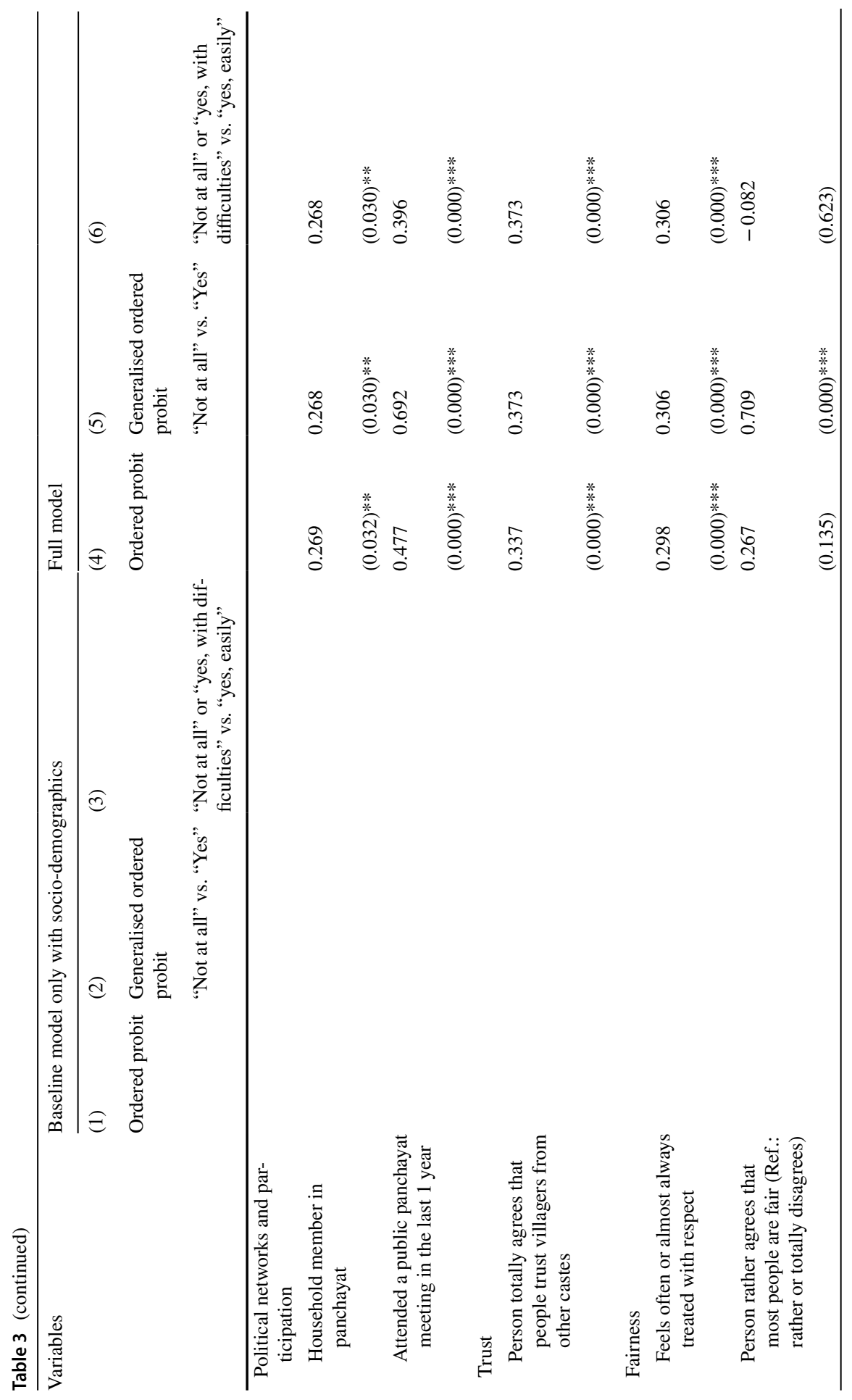




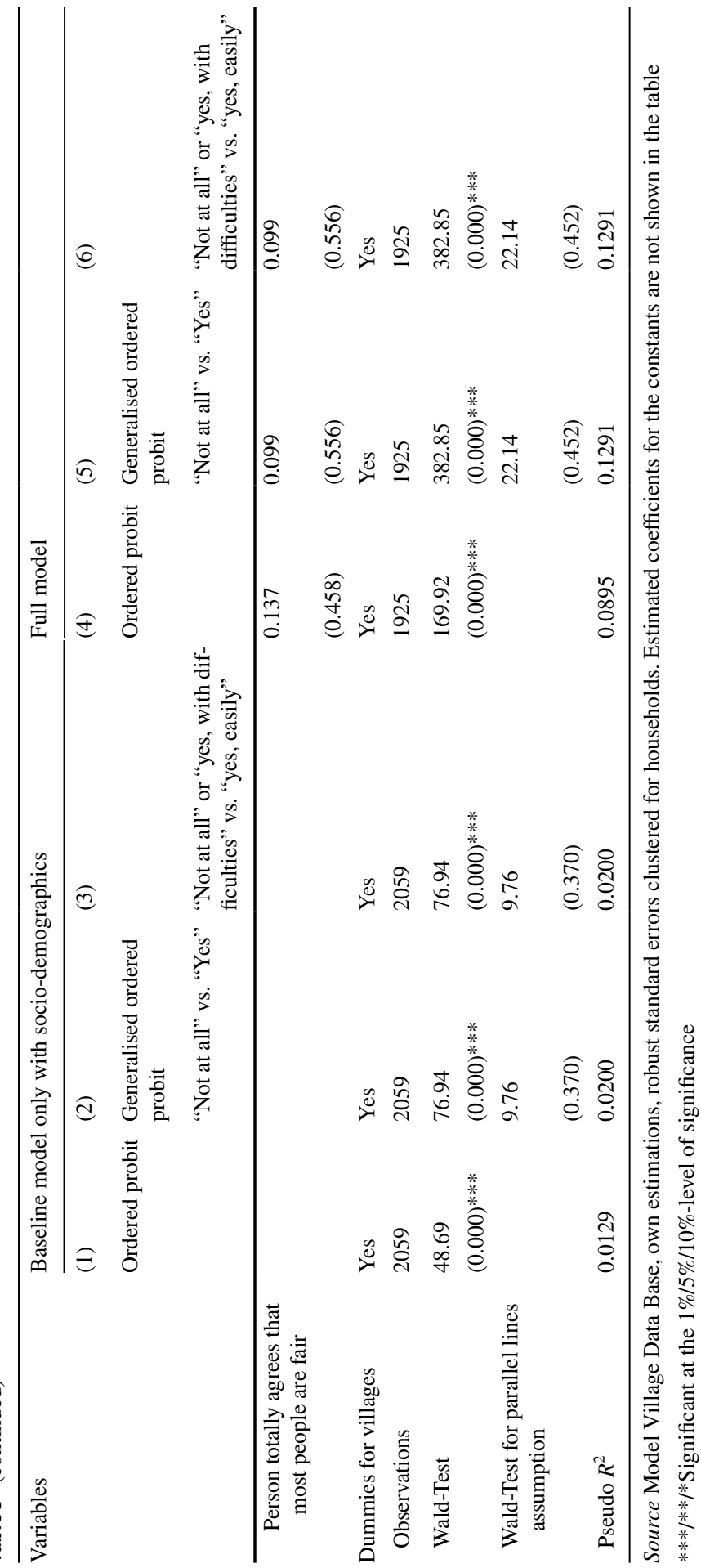

称 
- For marital status, all estimated coefficients are positive for married compared to non-married villagers. However, statistical significance is not given in these baseline models.

Table 3, columns (4) to (6), gives estimation results for the full model, now including variables for potential CA-based determinants of self-reported community-level impact.

With respect to the socio-demographic control variables, the significance of the gender and the age variable now disappear, mainly as these variables correlate with other explaining variables like education. However, being married can now be shown to correlate significantly with reported community-level impact.

Concerning the CA-based correlates, our estimation results underline that education is an important driver for community-level empowerment in rural India. Villagers who have successfully finished standards 4 to 10, or beyond, have a significantly higher probability to report influence for people like themselves at community level than villagers without school education. The marginal effect for the category, "easily", is about 6 percentage points for the group with 4 to 10 years of school $(P$-value $0.032)$ and 7.3 percentage points for those with beyond 10 years of school $(P$-value $0.094)$. The $P$-values are even lower in the generalised ordered probit estimations.

In line with the $\mathrm{CA}$, our findings also confirm that decent employment coincides with higher community-level empowerment. The self-reported feeling, to be able to bring about change in the community, is significantly lower for villagers working only as daily wage labourer and/or family worker. Compared to villagers who do not work, the marginal effect for the probability to be able to change "easily" is -8.6 percentage points. Compared to villagers who have any other type of work (e.g. employer, employee, self-employed, social work), the corresponding marginal effect is about -18.4 percentage points according to the ordered probit model. Thus, in this respect, our study confirms findings from previous research that unstable employment or employment solely within the family (see, e.g. Allendorf 2012) can limit an individual's autonomy and agency. ${ }^{1}$

Villagers searching for more work have a 6.1 percentage point higher probability to be able to bring about change easily than villagers who are not searching for more work. Assuming that searching for more work may indicate greater perceived individual agency to bring about change related to their employment situation, these villagers may also feel more empowered with others to have the collective agency to bring about change at the village level.

Our estimation results also provide weak evidence for a possible positive correlation between self-reported health and community-level empowerment: Within the ordered probit model the estimated coefficient of the health variable is significantly different from zero, but only at a $10 \%$-level of significance. Relaxing the proportional lines assumption, however, the generalised ordered probit model estimation

\footnotetext{
1 As "having decent work" positively correlates with the education of the villagers, we have estimated all models also with only one of them to check the robustness of our results against the problem of multicollinearity. The findings, however, do not depend on the model used.
} 
demonstrates that people who assess themselves as healthy (i.e. without any illness often in the last 1 year) have a substantially higher probability to report that change is easily possible.

The hypothesis that financial autonomy coincides with a higher degree of community-level empowerment is partly confirmed by our empirical findings. Villagers in households with savings and thus more financial autonomy report with higher probability that people like themselves may influence change (5\%-level of significance, $P$-value 0.025$)$. However, the level of household p.c. expenditure, and whether the household has debts, does not significantly correlate with communitylevel empowerment.

Other-regarding agency goals clearly correlate with self-reported impact on community-level change: Villagers who sometimes or often abstain from food to feed others have a significantly higher probability of reporting impact on communitylevel change. The marginal effect for "change easily" is 34.4 percentage points, thus particularly high. Members of poor families may feel a responsibility for their family and abstain from food to provide nutrition for other family members, notably children (Patel et al. 2015). As such, those who abstain from food, thereby repeatedly realising other-regarding agency goals in their family, may also be more willing and able to successfully contribute to other-regarding goals in their community.

Political networks and political participation seem to matter for the opportunity to impact changes at the village level: People from households with a panchayat member report significantly more often that people like themselves can bring change at the village level. The marginal effect for the outcome "can easily change" is 9.3 percentage points higher for individuals from households with panchayat members. Moreover, people attending public panchayat meetings report significantly more often that they can influence change at the community level.

Our empirical findings also provide evidence for trust as a precondition to bring about change in a community: Villagers who totally trust people from other castes in the village have an 11.6 percentage points higher probability to answer that impacting change is easily possible.

The feeling to be treated with respect clearly coincides with a higher reported impact on community-level change, which points toward a strong correlation between fairness and community-level empowerment. People who feel always or often to be treated with respect have a 10 percentage points higher probability to report that community-level changes are easily achievable $(P$-value 0.000$)$. Our estimation results thus underline that, without respect, assertiveness is perhaps not given as the position of the people will not be heard, or that a lower self-esteem might imply a lower power within the person. The corresponding variable for the individual perception of fairness of other people does not show a strong and systematic correlation with community-level empowerment. This difference in the findings for the two aspects of fairness considered may be due to the fact that the question "are you treated with respect" is specifically targeted at the person in question. As such, there is a high probability that a person who is not respected in a fair way refrains from trying to realise own agency goals due to the above-mentioned reasons. The assessment of the statement "most people are fair" is not targeted at the person interviewed, and thus less specific. 


\section{Empirical Findings for Men and Women}

In the following, we will examine to which degree the possible drivers of empowerment are relevant for both men and women. Our estimation results for men and women in Table 4 show similarities, but also substantial differences with respect to the role of the different drivers of community-level empowerment. As the variables for education and work are highly correlated, we present estimation models with and without the variables for "decent employment" and "search for more employment" in order to analyse the robustness of our findings against the potential multicollinearity problem. In the following, we summarise the main findings.

Considering the socio-demographic variables first, a positive effect of being married and a positive impact of age on community-level empowerment can only be observed for men, but not for women. With respect to marriage, realising changes at the community level requires time. In rural India, this may imply that men's time budgets are often disburdened by their wives. In contrast, family work and childcare frequently entail a limited time budget for married women. Moreover, they are often additionally limited with respect to their mobility in and beyond the village (Majumdar and Mooij 2016, p. 654). The age effect for men might be interpreted by the fact that women often stay dependent on men and the family and may not improve their social status with age as men may do.

Besides, men and women who have jobs other than daily wage labour and/or family work have a significantly higher probability to report perceived impact on community-level change than those who do either not work or who only do daily wage work or family work. Moreover, for women, the probability to report impact on change is significantly lower for daily wage workers and/or family workers than for women who do not work. In contrast, for men, there is no significant difference in community-level empowerment in that respect. This may be the consequence of the particularly low time budgets available for women who have to work as daily wage labourers in addition to their household responsibilities (which most men do not have). Furthermore, some women of higher-status households may not work, but instead may have more time to involve themselves in community-level activities as a benefit of their higher social statuses.

Rather similar findings for men and women can be found for the negative correlation of being head of the household with the reported influence on village-level change. With respect to the potential CA-based drivers of empowerment, the findings are at least quite consistent for men and women with respect to the role of otherregarding agency goals, the correlation between political networks and the impact on change (though the coefficients for having a household member in the panchayat are only significant for women, however, not for men) and the role of fairness for empowerment as measured by the feeling to be treated with respect (stronger for women than for men). Again, as in total, the variable for the general perception of the fairness of other people does not show a strong and systematic correlation with community-level empowerment for neither men nor women.

A positive impact of household savings as an indicator for financial autonomy can be clearly confirmed for women, and to a certain degree also for men, at least for the difference between "no change or only with difficulties" and "easy change". In 


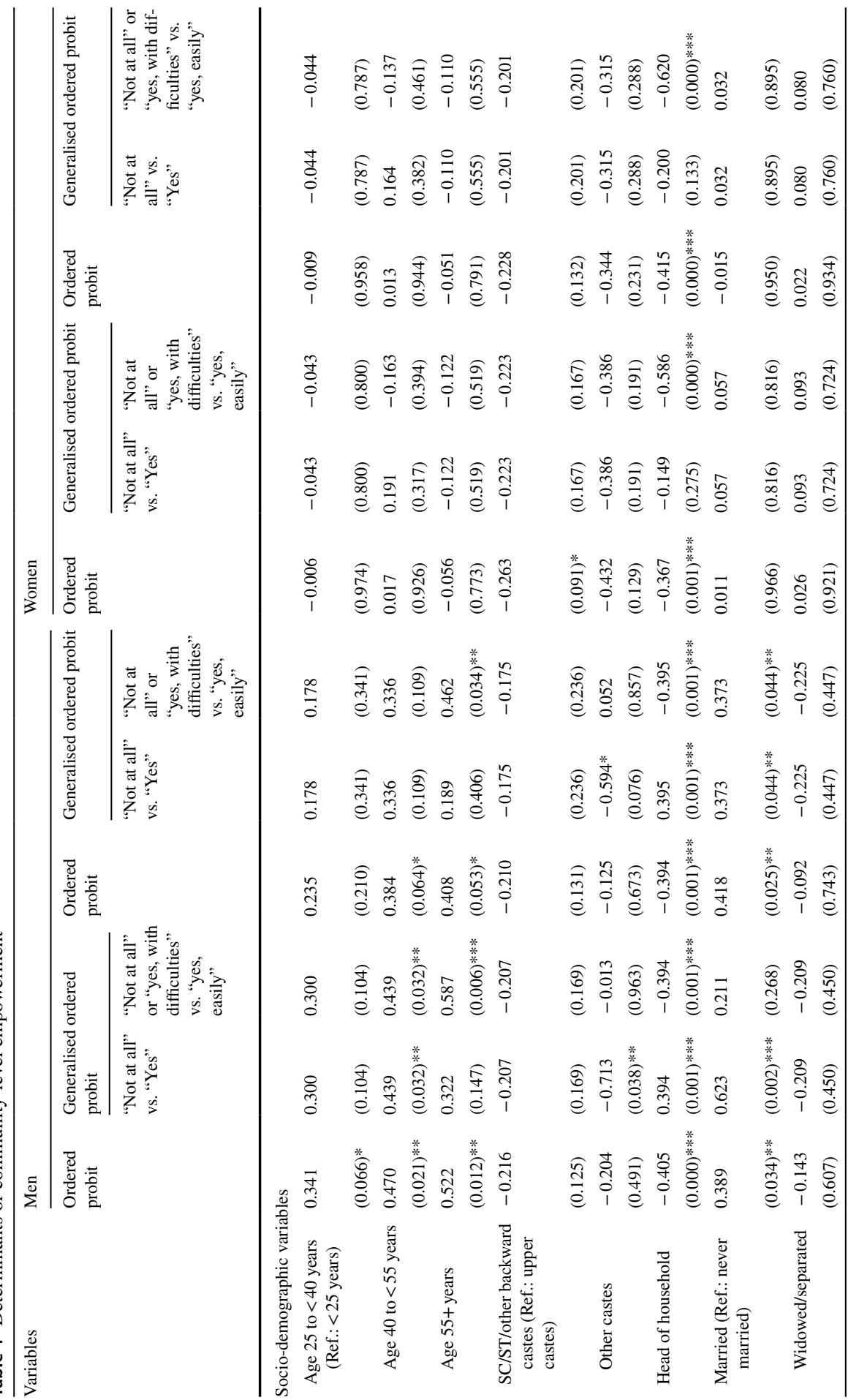




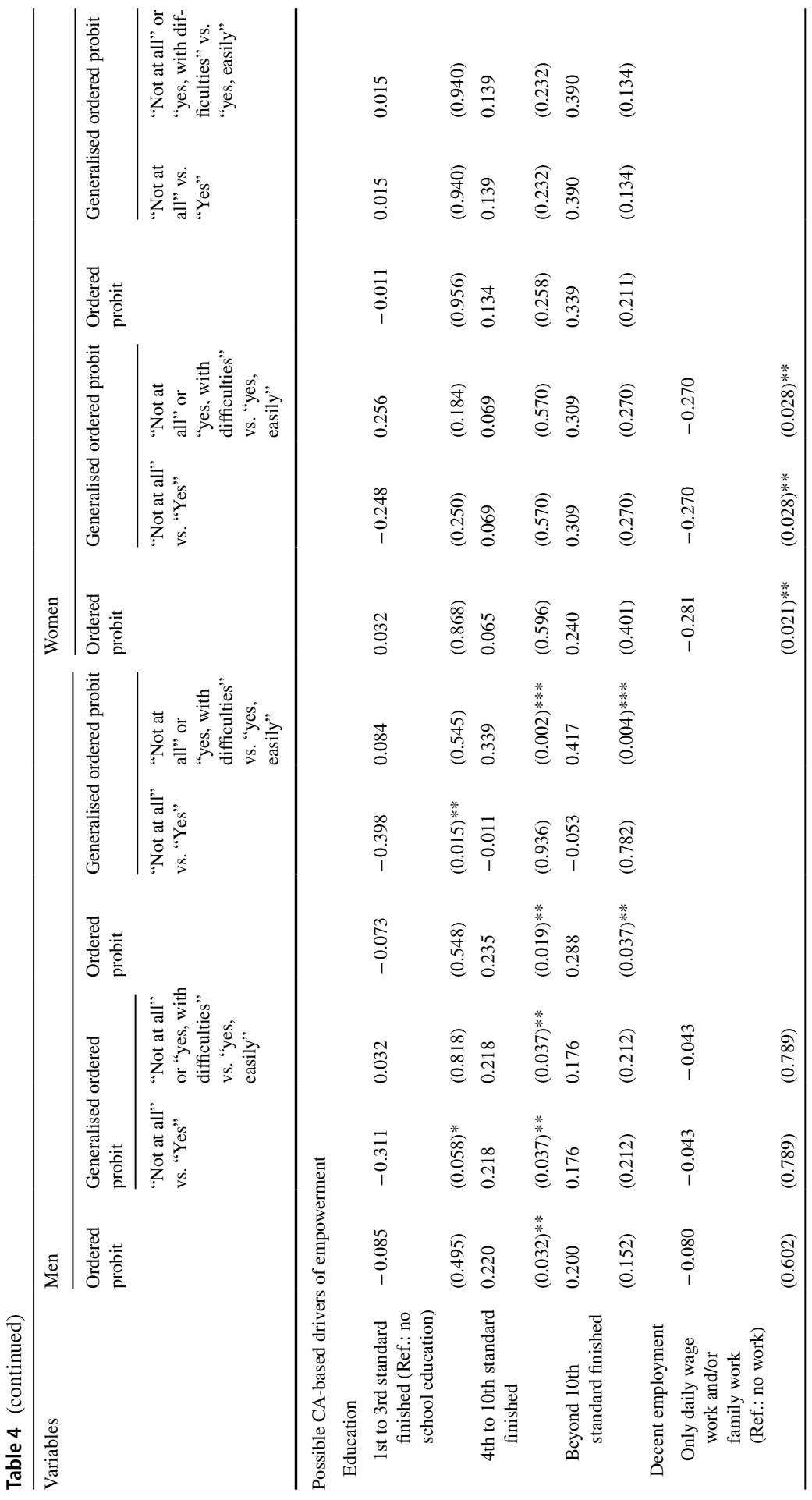




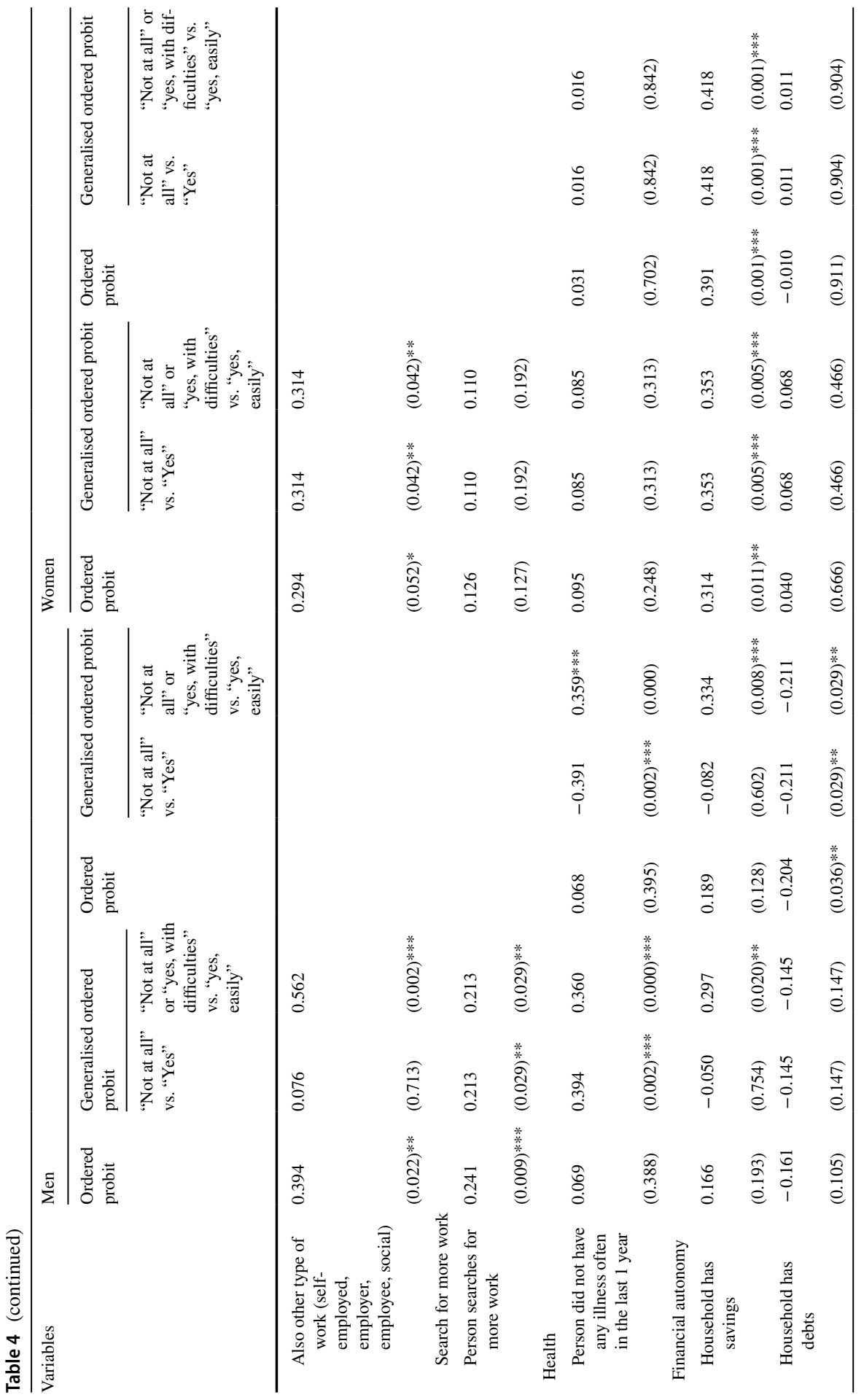




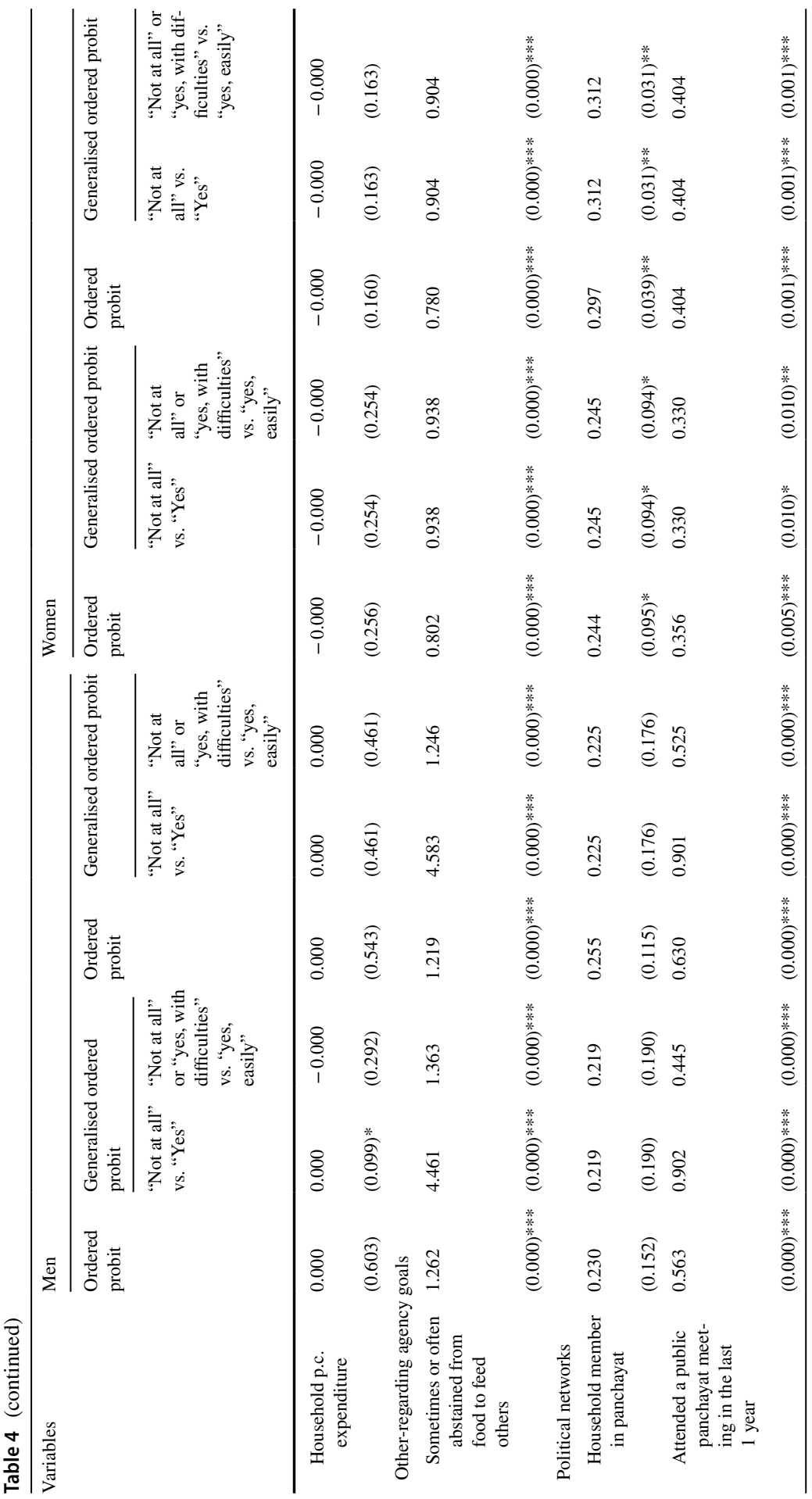




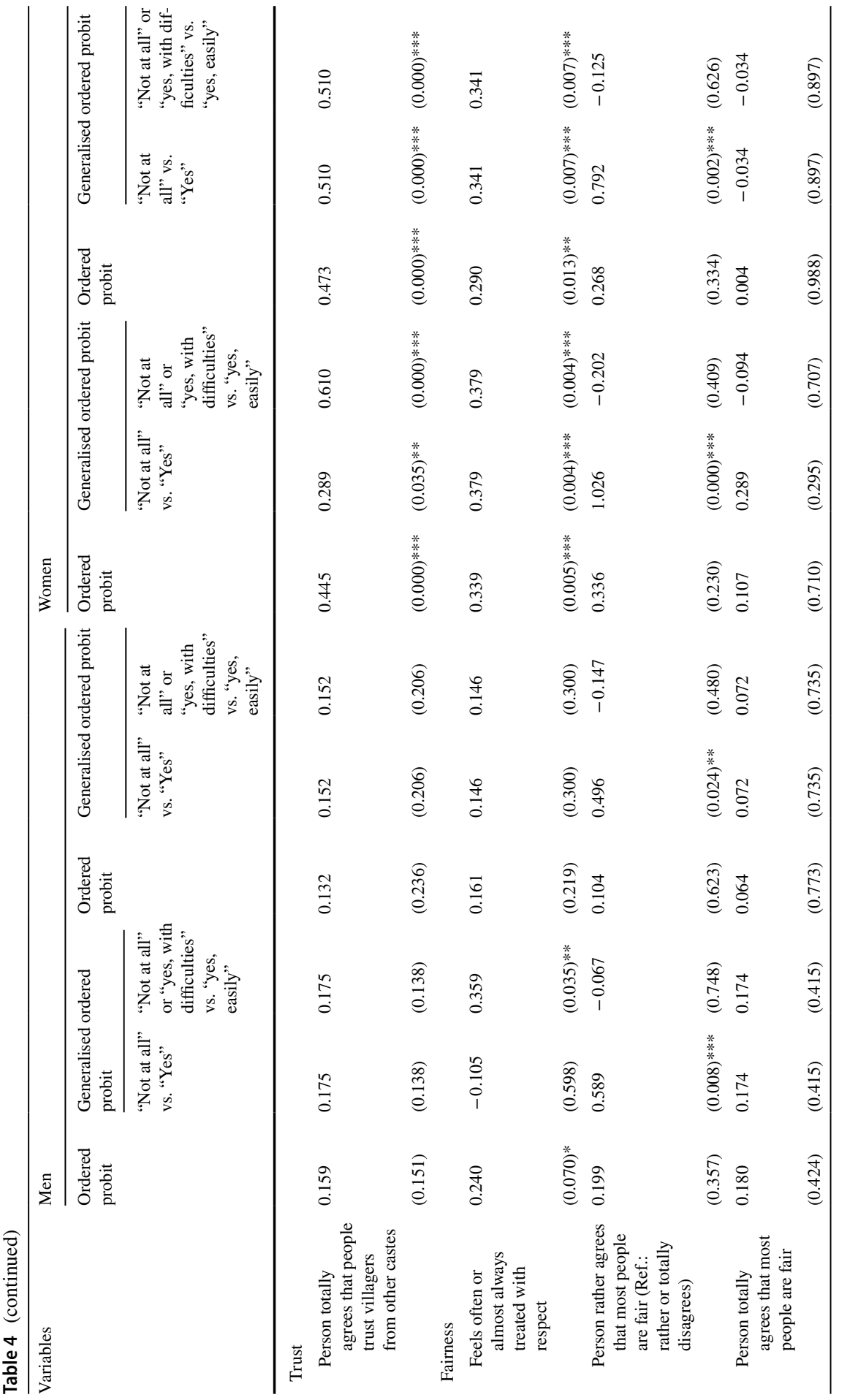




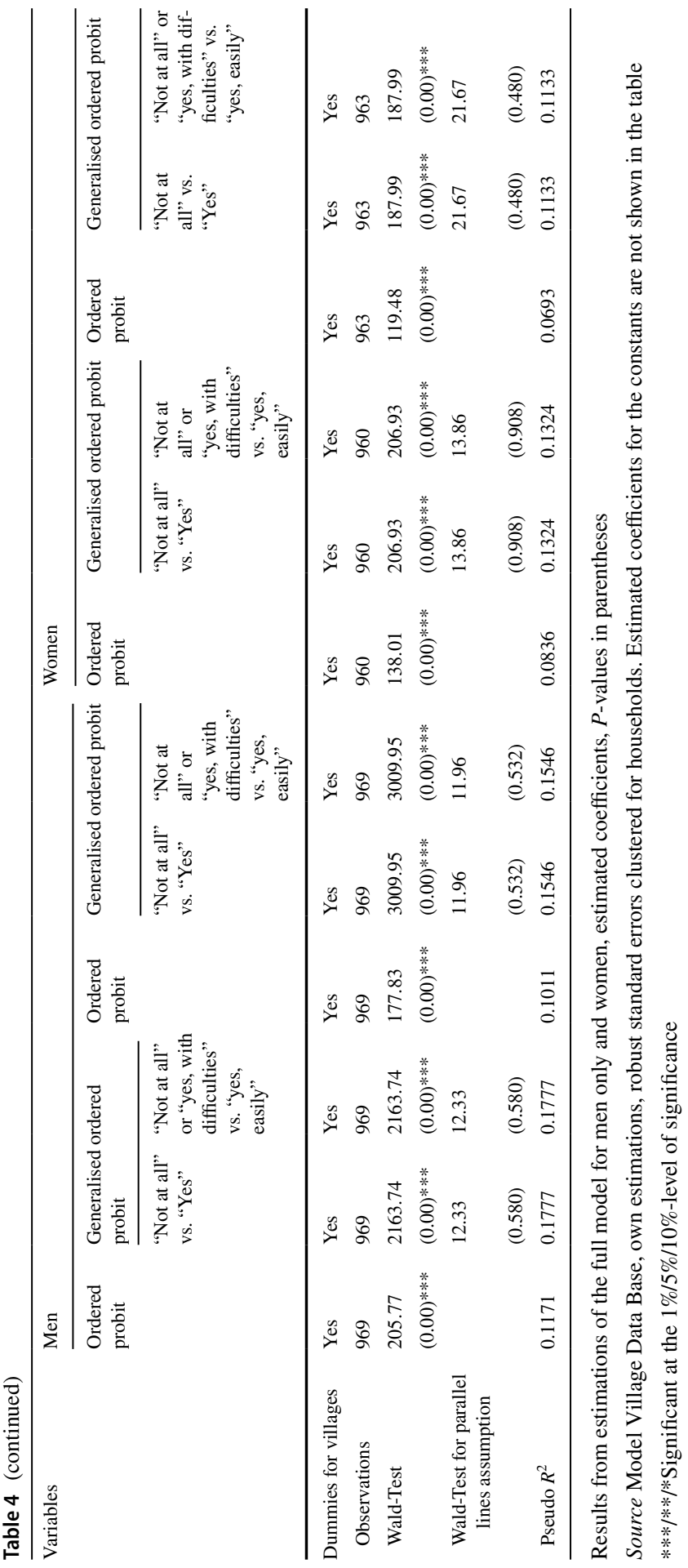


some models for men, the variable "household has debts" and the "level of household p.c. expenditure" also point towards a correlation of financial autonomy and community-level empowerment.

The findings for the education variable, in contrast, are quite different for men and women: a positive effect of education on the perceived impact of change can only be confirmed for men to a certain degree, however, not for women. The estimation results show that the impact of the education variable is weakened if the variables on the type of work are included at the same time. Thus, men seem to benefit from a higher education status, while for women, more education does not pay off in higher community-level empowerment. The different role models for men and women in India may again provide an explanation: men are mostly supposed to go for work, so that higher education often turns into a better job for them. Women, on the other hand, are not necessarily supposed to work outside their homes. Often, they are forced to live their life in "the rigors of household chores and the need to care for infants and the elderly, traditionally seen - quite unfairly - as women's responsibility" (Sen 2017, p. 30). In such a setting of other family members' pressure to stay at home (Anand et al. 2020), in which also educated women may find themselves, higher education will not be effective to empower these "housewives" at a community level.

\section{Conclusions and Need for Further Research}

This paper analyses two empowerment aspects that are often neglected in the literature: the empowerment of women and men, and community-level empowerment together with others ("power with").

A first main general finding is that a variety of CA-based indicators significantly correlate with community-level empowerment. Political networks and participation in the village show the expected positive impact on community-level empowerment. Moreover, trust and fairness, in the sense of social bases of self-respect, as indicators which capture preconditions of any cooperation, are also found to be positively correlated with community-level empowerment which requires a social cooperation with village members. Therefore, in cases of distrust, trust building, e. g. through mediation, can improve "power with" at the community level.

Our findings confirm the importance of other-regarding agency goals on different levels of empowerment. Respondents who abstain from food to feed others in the family report a higher impact on changes in the community.

An impact of education on women's community-level empowerment cannot be shown for our villages. In rural Karnataka, this may be due to patriarchal gender roles. They restrict women's autonomy to leave the house alone to participate in community-level decisions, which might be one reason why we find no impact of more education on female power in the community.

The assessment of determinants of empowerment for women and men separately has shown a variety of similarities. However, education, marriage, age and the type of work are associated with empowerment for men but not for women. Further research is needed to explain the underlying causes of these gender differences, 
which will help to understand how empowerment on a community level can be strengthened for women and men.

The paper concludes with some remarks with respect to its limitations. While the richness of self-reported data on a variety of CA dimensions is a strength of the data used, the empirical analyses are based on a cross-section of villagers. Therefore, our empirical findings should be interpreted as correlates, and not as causal effects, as the empirical estimates may suffer from an endogeneity bias. Panel data would make it possible to follow developments over time and to address this possible endogeneity bias. Moreover, it would also better allow accounting for a possible unobserved heterogeneity bias. Related to the endogeneity problem, the selection and interpretation of empowerment indicators can be difficult, as concepts of means and ends are not always clearly distinct and can be interrelated.

In some respects, our analyses are also limited by data availability. SHGs and SHG networks that can contribute substantially to empowerment typically of women (see, e.g. Anand et al. 2020; Datta 2015; or Tiwari 2014) exist in all four villages. However, in the context of this paper on community-level empowerment of men and women, a possible collective empowerment impact of SHGs cannot be analysed as SHG data are only available for women. Village dummy variables, therefore, at least take account for possible structural differences between the villages in SHG prevalence and participation. Furthermore, our variable to measure "other-regarding agency goals" focuses only on the family-level context as we do not have corresponding direct indicators at community-level. Notably indicators of other-regarding commitment related to the community would be desirable. It is also worth noting that our analysis is based on a subjective indicator of empowerment. While subjective measures are important regarding empowerment, they can also be biased, misperceived or adapted due to preferences that have been shaped by one's social or cultural context.

Further research should explore villagers' experiences, conditions and attitudes to find out whether visible, hidden or invisible power determines persisting power asymmetries in the villages. For example, by analysing whether a "community consensus" is shaped by free and broad public reasoning or by power relations. Furthermore, causes of powerlessness and respective remedies can be identified. The latter may, among others, strengthen the mobilisation and communication of the powerless in cases of visible and hidden power (Gaventa 1980, p. 27, 2006; Sen 2009). Addressing invisible power is also highly important: e. g. through conscientisation, i.e. strengthening the awareness and capacity of the powerless to reflect their perceptions and reality critically and to strive for change in the community. A further analysis should identify the diverse potentials that groups' collective empowerment has to overcome hidden and invisible power at the community level (Gaventa 2006; Ibrahim 2014).

Overall, our findings show that CA analyses can substantially enrich the empirical insights into the determinants of empowerment of women and men. Building on this, researchers and practitioners can identify factors which are worth addressing in order to improve empowerment with others in general as well as those determinants which are specific for women and men. 
Acknowledgements The authors thank Alejandra Boni and Jay Drydyk as well as two anonymous referees for their highly valuable comments which helped further improving the paper.

Funding Open Access funding enabled and organized by Projekt DEAL. The paper uses micro-level household and individual data generated within an independent scientific evaluation of the "Bayer CropScience Model Village Project (MVP)’. Survey costs are funded by Bayer CropScience.

Data Availability The datasets generated and/or analysed during the current study are not publicly available due to confidentiality reasons, but are available from the corresponding author on reasonable request.

\section{Compliance with Ethical Standards}

Conflict of interest On behalf of all authors, the corresponding author states that there is no conflict of interest.

Open Access This article is licensed under a Creative Commons Attribution 4.0 International License, which permits use, sharing, adaptation, distribution and reproduction in any medium or format, as long as you give appropriate credit to the original author(s) and the source, provide a link to the Creative Commons licence, and indicate if changes were made. The images or other third party material in this article are included in the article's Creative Commons licence, unless indicated otherwise in a credit line to the material. If material is not included in the article's Creative Commons licence and your intended use is not permitted by statutory regulation or exceeds the permitted use, you will need to obtain permission directly from the copyright holder. To view a copy of this licence, visit http://creativecommons.org/licen ses/by/4.0/.

\section{References}

Alkire, S., R. Meinzen-Dick, A. Peterman, A. Quisumbing, G. Seymour, and A. Vaz. 2013. The women's empowerment in agriculture index. World Development 52 (13): 71-91.

Allendorf, K. 2012. Women's agency and the quality of family relationships in India. Population Research and Policy Review 31 (2): 187-206.

Anand, P., S. Saxena, R. Gonzales, and H.A.H. Dang. 2020. Can women's self-help groups contribute to sustainable development? Evidence of capability changes from Northern India. Journal of Human Development and Capabilities 21 (2): 137-160.

Arora, R.U. 2014. Access to finance: An empirical analysis. European Journal of Development Research 26 (5): 798-814.

Burchi, F., P. de Muro, and S. Vicari. 2015. The development project as an institution of agency and capability expansion: The case of the Njombe Milk Project. European Journal of Development Research 27 (1): 19-36.

Chakrabarti, S., and C.S. Biswas. 2012. An exploratory analysis of women's empowerment in India: A structural equation modelling approach. The Journal of Development Studies 48 (1): 164-180.

Deininger, K., H.K. Nagarajan, and S. Paul. 2012. Can political reservations empower women and affect economic outcomes? Evidence from rural India. NCAER Working Papers on Decentralisation and Rural Governance in India, No. 4.

Datta, U. 2015. Socio-economic impacts of the JEEViKA: A large-scale self-help group project in Bihar, India. World Development 68 (C): 1-18.

Eyben, R., C. Harris, and J. Pettit. 2006. Introduction: Exploring power for change. IDS Bulletin 37 (6): $1-10$.

Frediani, A., J. Peris, and A. Boni. 2019. Notions of empowerment and participation: Contributions from and to the capability approach. In The capability approach, empowerment and participation. Concepts, methods and applications, ed. D.A. Clark, M. Biggeri, and A.A. Frediani, 101-124. London: Palgrave Macmillan. 
Garikipati, S. 2008. The impact of lending to women on household vulnerability and women's empowerment: Evidence from India. World Development 36 (12): 2620-2642.

Gaventa, J. 1980. Power and powerlessness: Quiescence and rebellion in an Appalachian Valley. Urbana: University of Illinois Press.

Gaventa, J. 2006. Finding the spaces for change: A power analysis. IDS Bulletin 37 (6): 23-33.

Greene, W.H. 2018. Econometric analysis. Global. London: Pearson Education.

Haagenars, A., K. de Vos, and M.A. Zaidi. 1994. Poverty statistics in the late 1980s: Research based on micro-data. Luxembourg: Office for Official Publications of the European Communities.

Ibrahim, S. 2014. The dynamics of collective agency in practice: Women's fight against FGM in Upper Egypt. In The capability approach. From theory to practice, ed. S. Ibrahim and M. Tiwari, 52-72. London: Palgrave Macmillan.

Ibrahim, S., and S. Alkire. 2007. Agency and empowerment: A proposal for internationally comparable indicators. Oxford Development Studies 35 (4): 379-403.

International Institute for Population Sciences (IIPS) and ICF. 2017. National Family Health Survey (NFHS-4), India, 2015-16: Karnataka, 25-28. Mumbai: IIPS.

Jejeebhoy, S.J., and Z.A. Sathar. 2001. Women's autonomy in India and Pakistan: The influence of religion and region. Population and Development Review 27 (4): 687-712.

Kishor, S., and K. Gupta. 2004. Women's empowerment in India and its states: Evidence from NFHS. Economic and Political Weekly 39 (7): 694-712.

Leach, F., and S. Sitaram. 2002. Microfinance and women's empowerment: A lesson from India. Development in Practice 12 (5): 575-588.

Lokshin, M., and M. Ravallion. 2005. Self-rated power and welfare in Russia. In Measuring empowerment: Cross-disciplinary perspectives, ed. D. Narayan, 177-195. Washington, DC: World Bank.

Lukes, S. 2005. Power. A radical view, 2nd ed. London: Red Globe Press.

Majumdar, M., and J. Mooij. 2016. Cultivating capabilities through activism: Examples from India. European Journal of Development Research 28 (4): 646-659.

Mitlin, D. 2013. Endowments, entitlements and capabilities-What urban social movements offer to poverty reduction. European Journal of Development Research 25 (1): 44-59.

Mosse, D. 2018. Caste and development: Contemporary perspectives on a structure of discrimination and advantage. World Development 110 (10): 422-436.

Narayan, D. 2005. Measuring empowerment: Cross-disciplinary perspectives. Washington, DC: World Bank.

Nussbaum, M. 2011. Creating capabilities. The human development approach. Cambridge: Harvard University Press.

Ostrom, E. 2000. Collective action and the evolution of social norms. Journal of Economic Perspectives 14 (3): $137-158$.

Patel, K., H. Gartaula, D. Johnson, and M. Karthikeyan. 2015. The interplay between household food security and wellbeing among small-scale farmers in the context of rapid agrarian change in India. Agriculture and Food Security 4 (1): 1-16.

Rawls, J. 1996. Political liberalism. New York: Columbia University Press.

Robeyns, I. 2017. Wellbeing, freedom and social justice. The capability approach re-examined. Cambridge: Open Book Publishers.

Sehnbruch, K., P. González, M. Apablaza, R. Mendez, and V. Arriagafa. 2020. The Quality of Employment (QoE) in nine Latin American countries: A multidimensional perspective. World Development 127 (3): 1-20.

Sen, A. 1983. Development: Which way now? The Economic Journal 93 (372): 745-762.

Sen, A. 1997. Inequality, unemployment and contemporary Europe. International Labour Review 136 (2): $155-171$.

Sen, A. 1999. Development as freedom. New York: Knopf.

Sen, A. 2009. The Idea of justice. London: Penguin.

Sen, A. 2017. Collective choice and social welfare. 2nd Expanded edition. London: Penguin.

Swain, R.B., and F.Y. Wallentin. 2009. Does microfinance empower women? Evidence from self-help groups in India. International Review of Applied Economics 23 (5): 541-556.

Tiwari, M. 2014. Capability approach, livelihoods and social inclusion: Agents for change in rural India. In The capability approach. From theory to practice, ed. S. Ibrahim and M. Tiwari, 29-51. London: Palgrave Macmillan.

Trommlerova, S.K., S. Klasen, and O. Leßmann. 2015. Determinants of empowerment in a capabilitybased poverty approach: Evidence from The Gambia. World Development 66 (C): 1-15. 
Volkert, J. 2006. European Union poverty assessment: A capability perspective. Journal of Human Development 7 (3): 359-383.

Williams, R. 2016. Understanding and interpreting generalized ordered logit models. The Journal of Mathematical Sociology 40 (1): 7-20.

Publisher's Note Springer Nature remains neutral with regard to jurisdictional claims in published maps and institutional affiliations.

Melinda Schmidt has graduated at Pforzheim University and Autonomous University of Barcelona and acts as research assistant in the project.

Harald Strotmann Professor of Economics at Pforzheim University in Germany.

Jürgen Volkert Professor of Economics at Pforzheim University in Germany. 